\title{
Socially Responsible Supply Chain Partnership Based-On CSR Equity Model
}

\author{
Rong Wang \\ Antai College of Economics \& Management, Shanghai Jiao Tong University, Shanghai, China. \\ Email: rwang@sjtu.edu.cn
}

Received May $24^{\text {th }}, 2012$; revised June $25^{\text {th }}, 2012$; accepted July $23^{\text {rd }}, 2012$

\begin{abstract}
Although China has become the world's second largest economy, a serious urgent issue of global consequences as well as the major obstacle in the process of China's economic development is the lack of CSR. Through CSR initiatives, enterprises of all sizes, in cooperation with their stakeholders, can help to reconcile economic, social and environmental ambitions. Socially responsible supply chain partnership that integrates all efforts of CSR activities from socially responsible enterprises to upstream partner-suppliers shall be surely needed within the uncertainly globalizing and networklizing knowledge economy era. This paper develops a five-step CSR Equity framework based-on socially responsible customer perspective for modeling and analysis of socially responsible supply chain partnership and shows relevant optimal coordination strategies to improving the social and environmental performance of all partners in the supply chain system. The findings suggest that the share rate of the total investment of partner-supplier's CSR efforts shall be the critical contract clause to coordinate the socially responsible supply chain partnership to implement Pareto optimal policy with cost sharing contract. Moreover, the share rate has a strong positive relativity with the ratio of marginal revenues between supply chain members, whereas negative relativity with the partner-supplier's leverage rate of CSR efforts.
\end{abstract}

Keywords: Socially Responsible Supply Chain; Supply Chain Partnership; Cost Sharing Contract; CSR Equity

\section{Introduction}

Even in recent years, nearly 70 or so percent of China's top enterprises which lack corporate social responsibilities (CSR) and play the roles of bystanders on promoting CSR exhibited in Table 1.

According to the latest research released by Chinese Academy of Social Sciences, the 2011 annual report on CSR of China, estimating the CSR development level of top 100 state-owned enterprises, as well as top 100 private enterprises and top 100 foreign-invested enterprises on their market responsibility, social responsibility, and environmental responsibility credentials, shows the survey findings in 2011 don't seem to have improved since the first report in 2009. The 2011 report estimates the market responsibility involved in customer responsibility, partner responsibility, and stockholder responsibility while the social responsibility embracing government responsibility, employee and community responsibility. Notably, it critically finds that the general level of Chinese CSR developing index in 2011 is still very low, only with the average score of 19.7 points on a scale of one hundred points [1].

Table 1. Phrase distribution of Chinese CSR development of top enterprises in 2010-2011.

\begin{tabular}{ccccc}
\hline & \multicolumn{2}{c}{2010} & & 2011 \\
\hline Phrase of CSR Development & Qty of Firms & \% of Total Qty & Qty of Firms & $\%$ of Total Qty \\
Elites (>80 points) & 1 & $0.3 \%$ & 1 & $0.3 \%$ \\
Leaders (60 - 80) & 13 & $4.3 \%$ & 23 & $7.7 \%$ \\
Pursuers (40 - 60) & 33 & $11.0 \%$ & 36 & $12.0 \%$ \\
Beginners (20 - 40) & 35 & $11.7 \%$ & 205 & $11.7 \%$ \\
Bystanders (<20) & 218 & $72.7 \%$ & $68.3 \%$ \\
\hline
\end{tabular}


Although China has become the world's second largest economy with Japan surrendering its 42-year-old ranking after its economy shrank in the final months of 2010, one serious urgent issue of global consequences as well as a major obstacle in the process of China's economic development is the lack of CSR involving in customer responsibility, transaction process responsibility, employee responsibility, suppliers responsibility, community responsibility, environment responsibility, and so forth. It is urgent time for enterprises to be aware of global responsibility and harmonious social consciousness to sustainable development, and voluntarily integrate the CSR into their business strategy to pursue a natural fit between economic values and environmental and social benefits.

\subsection{Nature of CSR and Its Conceptual Model}

The father of CSR Bowen whose landmark book "Social Responsibilities of the Businessman" is argued to mark the beginnings of the modern period of literature on the issue of social responsibility, and sets forth an initial definition of the social responsibilities of businessmen: "It refers to the obligations of businessmen to pursue those policies, to make those decisions, or to follow those lines of action which are desirable in terms of the objectives and values of our society" [2]. In 1971 the Committee for Economic Development used the Three Concentric Circles Model for depicting the concept of CSR: The inner circle included basic economic functions such as products, jobs and growth; The intermediate circle suggested that the economic functions must be exercised with a sensitive awareness of changing social values and priorities; And the outer circle outlined newly emerging and still amorphous responsibilities that business should assume to become more actively involved in improving the social environment [3]. Carroll traced the evolution of the CSR concept and proposed a universal four-part definition of CSR as following: "The social responsibility of business encompasses the economic, legal, ethical, and discretionary expectations that society has of organizations at a given point in time" [4,5].

From the viewpoint of stakeholder theory, the nature of CSR is that the enterprises should be responsible for a broader set of stakeholders and the business environment in a way that ensures the long-term sustainable success of the enterprises. Freeman defined the stakeholders as "any group or individual who is affected by or can affect the achievement of an organization's objectives" [6]. Wartick and Coghran traced the evolution of the corporate social performance model by focusing on three challenges to the concept of CSR: Economic responsibility, public responsibility, and social responsiveness [7]. The green business guru Elkington convincingly argues as well that 21 st century business leaders should satisfy the triple bottom line that is economic, social and environmental sustainability [8]. For promoting CSR, the United Nations Global Compact is launched in 2000 as a strategic policy initiative for businesses that are committed to aligning their operations and strategies with ten universally accepted principles in the four areas of human rights, labor, environment and anti-corruption [9]. According to the standard definition of the European Commission which describes CSR as "a two-dimensional concept whereby companies integrate social and environmental concerns in their business operations and in their interaction with their stakeholders on a voluntary basis" [10].

In short, this paper outlines the conceptual model of CSR embraced three kinds of social responsibilities: Economic, social and environmental. It is attributed to the value creation of any kind of corporate social responsibilities will be depended on the fulfillments by enterprises and supervisions of all relevant stakeholders of CSR. To be sure, the core values of the harmonious and sustainable society, that is, our human being wish to live in a harmonious world which respects all the people and nature. Through CSR initiatives, enterprises of all sizes, in cooperation with their stakeholders, can help to reconcile economic, social and environmental ambitions.

\subsection{CSR Initiatives in the Socially Responsible Supply Chain System}

Nowadays the general agreement on the new notion of "product" is defined not only embedding with goods and services, but also social and environmental behaviors and obligations. And the enterprises, large or small, shall commit to social accountable conduct, full compliance to applicable national and international laws and respect for human rights in the spirit of internationally recognized social accountable standards, such as SA8000 [11]. The SAI's first social accountability system, SA8000, is a way for retailers, distributors, manufacturers, suppliers and other organizations to maintain just and decent working conditions throughout the supply chain. Furthermore the SA8000 firms are required to apply these same standards to their own suppliers and to support this through monitoring social accountable practices.

CSR issues surrounding the supply chains have only recently come to the fore, especially, in the context of conceptual and survey studies. Carter and Dresner examined environmental risks in supply management [12]. Roberts concerned labor practices of ethical sourcing initiatives [13]. Carter and Jennings empirically studied the role of purchasing in corporate social responsibility [14]. Wang focused on social responsible supply coordinating relationship and strategies based on the social responsible "relational rent" [15]. Cruz considered the be- 
haviors of various decision makers on the impact of corporate social responsibility in supply chain management and showed that social responsibility activities can potentially reduce transaction costs, risk and environmental impact [16]. Nevertheless, socially responsible supply chain partnerships that integrate all efforts of CSR from socially responsible enterprises to upstream partner-suppliers shall be surely needed within the uncertainly globalizing and networklizing knowledge economy era. The purpose of this paper is to develop a CSR Equity framework based-on socially responsible customer perspective for modeling and analysis of socially responsible supply chain partnership and show relevant optimal coordination strategies to the economic, social and environmental performance of all partners in the socially responsible supply chain system.

The remainder of the paper is organized as follows. In the next section, we will firstly examine the potential relationship between the CSR initiatives and performances with an eye toward developing a CSR Equity framework based-on socially responsible customer perspective. The third section will explore the basic models and assumptions of socially responsible supply chain partnership based-on the CSR Equity model. Then, the fourth and fifth sections will analyze and present the key finds of the study on socially responsible supply chain coordination strategy with cost sharing contract, followed by the concluding remarks in the last section.

\section{CSR Equity Framework Based-On Socially Responsible Customer Perspective}

A variety of theories and methodologies has been employed to study the potential relationship between the CSR initiatives and performances.

\subsection{Literature Review in CSR Initiatives-Performances Relationship}

Griffin and Mahon categorized 62 research results as reported in 51 articles (spanning 25 years of research) and created a table with three categories of the relationship between CSR and corporate financial performance: a positive correlation; a negative correlation; and no effect. As a result, they concluded that there were 20 studies showing a negative correlation, 9 studies in the positive relationship and the others in the no effect/inconclusive relationship. Obviously, the overall impact of the studies reviewed is showing a negative correlation between CSR and corporate financial performance [17]. Instead, based on the above study of Griffin and Mahon, Roman, Hayibor and Agle recategorized the same 51 articles and reconstructed Griffin and Mahon's table and showed 33 studies in the positive relationship, 14 studies in the no effect/inconclusive relationship, and 5 studies in the negative relationship. It can be seen that most of the studies reviewed show positive relation between CSR and corporate financial performance [18].

Preston and O'Bannon have analyzed the relationship between indicators of CSR and financial performance within a comprehensive theoretical framework. They firstly have distinguished between the direction of the CSR-financial performance relationship (positive, negative or neutral) and the causal sequence: Does CSR influence financial performance, does financial performance influence CSR, or is there a synergistic relationship between the two? And then they have developed six possible causal and directional hypotheses involved in tradeoff hypothesis, social impact hypothesis, slack resources hypothesis, managerial opportunism hypothesis, positive synergy hypothesis and negative synergy hypothesis [19]. Kapoor and Sandhu have examined the impact of CSR on corporate financial performance in terms of profitability and growth and concluded significant positive impact of CSR on corporate profitability and insignificant positive impact on corporate growth [20].

The trade-off hypothesis supposes a negative impact of CSR on financial performance. This hypothesis deals with the neoclassical economists' position which holds that socially responsible behavior will net few economic benefits while its numerous costs will reduce profits and shareholder wealth [21]. Makni, Francoeur and Bellavance find that, at least in the short run, with the trade-off hypothesis and, in part, with the negative synergy hypothesis which states that socially responsible firms experience lower profits and reduced shareholder wealth, which in turn limits the socially responsible investments [22].

Whereas, the social impact hypothesis is based on the stakeholder theory which suggests that meeting the needs of various corporate stakeholders will lead to favorable financial performance. Orlitzky, Schmidt and Rynes apply the Meta-Analysis to theorize on the relationship between corporate social/environmental performance (CSP) and corporate financial performance (CFP). And their meta-analytic findings suggest that CSP reputation indices are more highly correlated with CFP than are other indicators of CSP [23]. Proponents of the stakeholder theory of the corporation argue that favorable social performance is a requirement for business legitimacy and that social and financial performances tend to be positively associated over the long term.

\subsection{CSR Equity Model}

The CSR efforts mirror the core values of the harmonious society, that is, our human being wish to live in a harmonious world which respects all the people and nature. In the early literatures on CSR, Webster determines 
the characteristics of the socially conscious consumer and provides the most comprehensive definition of the socially conscious consumer as "a consumer who takes into account the public consequences of his or her private consumption or who attempts to use his or her purchasing power to bring about social change" [24]. On the basis of Webster's significant research, Roberts and Mohr set forth the concept of socially responsible consumer behavior and define socially responsible consumer behavior as a person basing his or her acquisition, usage, and disposition of products on a desire to minimize or eliminate any harmful effects and maximize the long-run beneficial impact on society. And then, the socially responsible consumer behavior requires the inclusion of CSR as one of the criteria influencing a person's consumption patterns $[25,26]$.

CSR has a strong relativity with corporate reputation just like the two sides of a same coin, for example, the developments depart from the more voluntary forms of CSR favored in the USA and are having a significant effect on the reputation-building strategies of global companies in many countries [27-29]. Specially, the qualitative study of Hillenbrand and Money suggest that there is considerable similarity between the concepts of responsibility and reputation. Implications may include the use of reputation models as potential measures for many of the aspects conceptualized as responsibility. While the corporate reputation is a multi-stakeholder concept that is reflected in the perceptions that stakeholders have of an organization [30]. Brown and Dacin recognize that Negative CSR associations can have a detrimental effect on overall product evaluations, whereas positive CSR associations can enhance product evaluations [31]. Sen and Bhattacharya examined consumer reactions to CSR initiatives with finding that CSR efforts can affect consumers' intentions to purchase its products both indirectly and directly and highlighting the mediating roles of consumers' perceptions of congruence between their own characters and that of the company in their reactions to its CSR initiatives [32].

As a consequence, on the basis of the fore research literatures, this paper proposes a five-step CSR Equity framework based-on socially responsible customer perspective in Figure 1 for modeling and analysis of socially responsible supply chain partnership, which maps out component analysis and management of CSR equity.

It is clearly seen from Figure 1, the CSR Equity model is thought of five steps. The starting steps are to build and enhance the positive and trustworthy corporate reputation in virtue of voluntary and sustainable CSR efforts to reconcile economic, social and environmental benefits. Then the third step is to create the strong and favorable CSR associations through corporate reputation transmis- sion. The fourth step is to elicit and spread intense and desirable customer reactions to CSR initiatives. And the final step is to forging and foster socially responsible customer loyalty, which can be broken down into two key dimensions: Behavioral loyalty (as well as purchase loyalty) and attitudinal loyalty [33]. Both attitudinal loyalty and behavioral loyalty link to better socially responsible consumer intentions and consumer behavior. As a result, the socially responsible consumer would avoid buying products from companies that harm society and actively seek out products from companies that help society.

\section{Basic Models and Assumptions}

Consider a socially responsible supply chain consists of two members: One socially responsible manufacturer and one upstream partner-supplier. Firstly, the notations and assumptions in the models developed will be stated in details as follows.

According to the above CSR Equity model in Figure 1, the voluntary and sustainable CSR efforts to reconcile economic, social and environmental benefits are foundations in building the CSR equity regarded as vital intangible assets to corporate equity, which is determined by the positive and trustworthy corporate reputation linking to better socially responsible consumer intentions and consumer behavior, that is, with greater market share and premium in the marketplace.

Suppose the socially responsible manufacturer and the upstream partner-supplier can exert the total investment

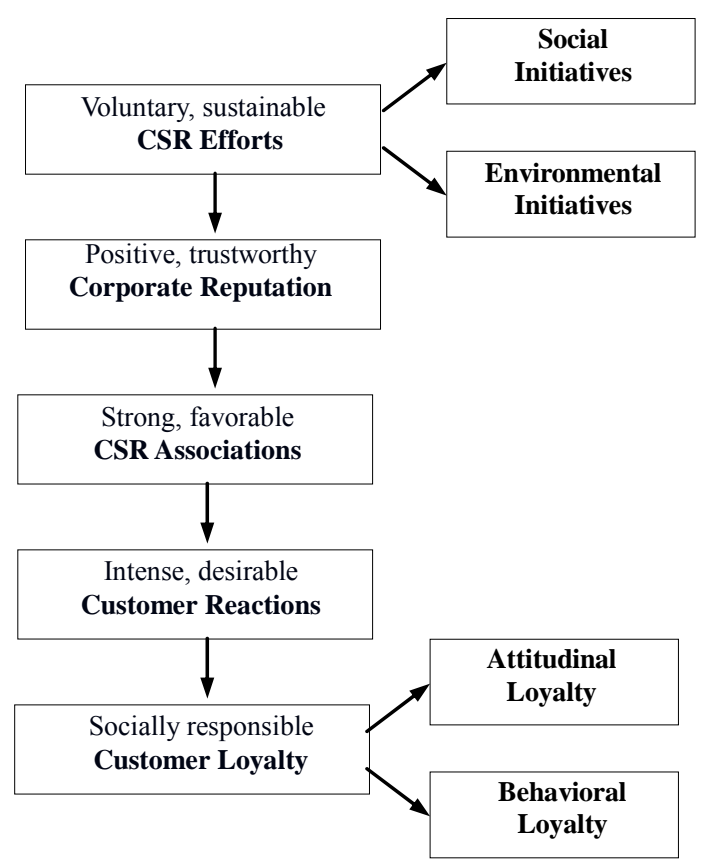

Figure 1. CSR equity framework based-on socially responsible customer perspective. 
on CSR efforts $e_{m}$ and $e_{s}$, respectively. Clearly the market demand functions about aggregate impact of both of the above investment parameters can be given by $D\left(e_{m}, e_{s}\right)$, where letting $D\left(e_{m}, e_{s}\right)$ be continuously differentiable on $\left(e_{m}, e_{s}\right) \in(0, \infty) \times(0, \infty)$ and using right-hand derivatives at 0 , strictly increasing in both investment parameters. And then we can find the socially responsible manufacturer expected market demand under the positive and trustworthy corporate reputation is

$$
D\left(e_{m}, e_{s}\right)=D_{0}-e_{m}^{-\alpha} e_{s}^{-\beta}
$$

where $D_{0}, \alpha$ and $\beta$ are constants; $\alpha$ and $\beta$ are the leverage rate of CSR efforts $e_{m}$ and $e_{s}$, respectively, $\alpha \geq 0, \beta \geq 0$; $D_{0}$ is the potential market demand which is implemented relying on both CSR efforts $e_{m}$ and $e_{s}$, that is, either $e_{m}$ or $e_{s}$ is 0 , the actual market demand $D\left(e_{m}, e_{s}\right)$ shall turn to be disappeared due to the infinitely negative leverage rate of CSR efforts $e_{m}$ or $e_{s}$, which can be attribute to those socially responsible consumers would avoid buying products from bystanders and companies that harm society and prefer actively to seek out products from the socially responsible enterprises.

Finally, consider the socially responsible manufacturer and the upstream partner-supplier can gain the marginal revenue $M R_{m}$ and $M R_{s}$, respectively, and suppose $M R_{m}$ and $M R_{s}$ are constants for simplifying the analysis further. Thus, we now define that the socially responsible manufacturer's and the upstream partner-supplier's expected revenue function under the positive and trustworthy corporate reputation is as shown by expresses (2) and (3), respectively:

$$
\begin{aligned}
\pi_{m}\left(e_{m}, e_{s}\right) & =M R_{m} \cdot D\left(e_{m}, e_{s}\right)-e_{m} \\
& =M R_{m} \cdot\left(D_{0}-e_{m}^{-\alpha} e_{s}^{-\beta}\right)-e_{m} \\
\pi_{s}\left(e_{m}, e_{s}\right)= & M R_{s} \cdot D\left(e_{m}, e_{s}\right)-e_{s} \\
= & M R_{s} \cdot\left(D_{0}-e_{m}^{-\alpha} e_{s}^{-\beta}\right)-e_{s}
\end{aligned}
$$

At first, the solution concept used in this section is from the view in non-cooperative static games: The two supply chain members choose optimally strategies simultaneously and are thereafter committed to their chosen strategies, i.e., these are simultaneous move, one-shot games. So we have the following:

$$
\begin{aligned}
& \max _{r, e_{s}} \pi_{m}=\max _{r, e_{s}}\left[M R_{m} \cdot\left(D_{0}-e_{m}^{-\alpha} e_{s}^{-\beta}\right)-e_{m}\right] \\
& \text { s.t. } 0 \leq r \leq 1, e_{s} \geq 0 \\
& \max _{r, e_{m}} \pi_{s}=\max _{r, e_{m}}\left[M R_{s} \cdot\left(D_{0}-e_{m}^{-\alpha} e_{s}^{-\beta}\right)-e_{s}\right] \\
& \text { s.t. } 0 \leq r \leq 1, e_{m} \geq 0
\end{aligned}
$$

From differentiation using the first order condition for $e_{m}$ and $e_{s}$, respectively,

$$
\begin{aligned}
& \frac{\partial \pi_{m}}{\partial e_{m}}=M R_{m} \cdot \alpha e_{m}^{-\alpha-1} e_{s}^{-\beta}-1=0 \\
& \frac{\partial \pi_{s}}{\partial e_{s}}=M R_{s} \cdot \beta e_{m}^{-\alpha} e_{s}^{-\beta-1}-1=0
\end{aligned}
$$

Thus the Nash equilibrium in non-cooperative static games is obtained

$$
\begin{aligned}
e_{m}^{*} & =\left(\frac{1}{M R_{m} \cdot \alpha e_{s}^{-\beta}}\right)^{\frac{1}{-\alpha-1}} \\
& =\left[\frac{\left(\alpha \cdot M R_{m}\right)^{\beta+1}}{\left(\beta \cdot M R_{s}\right)^{\beta}}\right]^{\frac{1}{\alpha+\beta+1}} \\
e_{s}^{*} & =\left(\frac{1-r}{M R_{s} \cdot \beta e_{m}^{-\alpha}}\right)^{\frac{1}{-\beta-1}} \\
& =\left[\frac{\left(\beta \cdot M R_{s}\right)^{\alpha+1}}{\left(\alpha \cdot M R_{m}\right)^{\alpha}}\right]^{\frac{1}{\alpha+\beta+1}}
\end{aligned}
$$

As $\alpha \geq 0, \beta \geq 0$, observe the above expresses (8) and (9) that the optimal CSR efforts' strategy $e_{m}^{*}$ and $e_{s}^{*}$ are positive relevant with the member's marginal revenue (i.e. $M R_{m}, M R_{s}$ ) and the leverage rate of CSR efforts (i.e. $\alpha, \beta)$, respectively, whereas negative relevant with the partner's marginal revenue (i.e. $M R_{s}, M R_{m}$ ) and the leverage rate of CSR efforts (i.e. $\beta, \alpha$ ), respectively. Thus, it is easy to see that

[Proposition 1] No one of supply chain members has incentive to implement Pareto optimal policy for socially responsible supply chain partnership in non-cooperative static games.

\section{Cost Sharing Contract Coordination}

In this section, considering in the case of socially responsible supply chain coordination strategy with cost sharing contract, the socially responsible manufacturer shall provide seriously a share rate of $r(0 \leq r \leq 1)$ of the total investment of upstream partner-supplier's CSR efforts $e_{s}$, while the upstream partner-supplier will be proposed a share proportion of $(1-r)$ as $0 \leq r \leq 1$.

The solution concept used in this section is subgame perfect equilibrium. Consequently, as the Stackelberg follower, the upstream partner-supplier makes the own investment strategy of the CSR efforts is dependent upon the corresponding "share rate $r$ " of coordination strategy with cost sharing contract of the downstream partner. For the socially responsible manufacturer may offer a "share rate $r$ " as the incentive for the upstream partner-supplier to increase CSR efforts and to be socially responsible partner integrated into the social responsible supply chain 
so as to improve the own positive and trustworthy corporate reputation. Thus it can be seen, as the Stackelberg leader, the socially responsible manufacturer must make the investment of CSR efforts and "share rate $r$ " of coordination strategy with cost sharing contract first and then the partner-supplier observes this strategy and makes his own investment strategy choice.

Consider the above Stackelberg equilibrium policy, letting the socially responsible manufacturer first make investment level $e_{m}$ on its own CSR efforts and "share rate $r$ " of the investment of partner-supplier's CSR efforts.

In virtue of backwards induction, firstly, find the partner-supplier's optimal CSR efforts' policy as a response to any strategies made by the Stackelberg leader:

$$
\begin{aligned}
\frac{\partial \pi_{s}}{\partial e_{s}} & =\frac{\partial\left[M R_{s} \cdot\left(D_{0}-e_{m}^{-\alpha} e_{s}^{-\beta}\right)-(1-r) e_{s}\right]}{\partial e_{s}} \\
& =M R_{s} \cdot e_{m}^{-\alpha} e_{s}^{-\beta-1}-(1-r)=0
\end{aligned}
$$

As a result, the investment of partner-supplier's CSR efforts generated is expressed as following

$$
e_{s}^{* *}=\left(\frac{\beta \cdot M R_{s}}{(1-r) \cdot e_{m}^{\alpha}}\right)^{\frac{1}{\beta+1}}
$$

As $\alpha \geq 0, \beta \geq 0,0 \leq r \leq 1$, then the following propositions may be given from the express (11),

[Proposition 2] The optimal CSR efforts' strategy $e_{s}^{* *}$ for partner-supplier is positive relevant with the "share rate $r$ ", besides his marginal revenue (i.e. $M R_{s}$ ) and his leverage rate of CSR efforts (i.e. $\beta$ );

[Proposition 3] The optimal CSR efforts' strategy $e_{s}^{* *}$ is negative relevant with his downstream partner exerting the total investment on CSR efforts $e_{m}$ and leverage rate of CSR efforts (i.e. $\alpha$ ).

Given the results of these two propositions, it can be able to observe that, in addition to the marginal revenue $M R_{s}$ and leverage rate of CSR efforts $\beta$, the partner-supplier only has incentive to increase his investment on CSR efforts as the socially responsible manufacturer increases the "share rate $r$ ". Even if the socially responsible manufacturer solely increases investment level $e_{m}$ and the leverage rate $\alpha$ on his own CSR efforts, the partner-supplier prefer to be a "free-rider" of partner's corporate reputation effect so as to have incentive to reduce the investment on CSR efforts instead.

Secondly, find the optimal CSR policy for the socially responsible manufacturer anticipating the response by the upstream partner-supplier.

$$
\begin{aligned}
& \max _{r, e_{s}} \pi_{m}=\max _{r, e_{s}}\left[M R_{m} \cdot\left(D_{0}-e_{m}^{-\alpha} e_{s}^{-\beta}\right)-e_{m}-r e_{s}\right] \\
& \text { s.t. } 0 \leq r \leq 1, e_{s} \geq 0
\end{aligned}
$$

Intuitively, the socially responsible manufacturer chooses the best possible point on the follower's best response function.

$$
\begin{aligned}
& \max _{r, e_{s}^{* *}} \pi_{m} \\
& =\max _{r, e_{s}^{* *}}\left\{M R_{m} \cdot\left[D_{0}-e_{m}{ }^{-\alpha}\left(e_{s}^{* *}\right)^{-\beta}\right]-e_{m}-r\left(e_{s}^{* *}\right)\right\} \\
& \text { s.t. } 0 \leq r \leq 1, e_{s}^{* *} \geq 0
\end{aligned}
$$

Differentiating this expression with respect to $\pi_{m}$ and $r$ yields,

$$
\begin{aligned}
\frac{\partial \pi_{m}}{\partial r} & =\frac{\partial\left\{M R_{m} \cdot\left[D_{0}-e_{m}^{-\alpha}\left(e_{s}^{* *}\right)^{-\beta}\right]-e_{m}-r\left(e_{s}^{* *}\right)\right\}}{\partial e_{m}} \\
& =0
\end{aligned}
$$

Thus,

$$
r^{* *}=1-\frac{1}{\frac{M R_{m}}{M R_{s}}-\beta}, \frac{M R_{m}}{M R_{s}} \geq \beta+1
$$

Considering $0 \leq r \leq 1$, only as $\frac{M R_{m}}{M R_{s}} \geq \beta+1$, the socially responsible manufacturer shall provide the "share rate $r "(0 \leq r \leq 1)$ for the upstream partner-supplier's CSR efforts. And propositions is given below.

[Proposition 4] The "share rate $r$ " is positive relevant with firm's marginal revenue (i.e. $M R_{m}$ );

[Proposition 5] The "share rate $r$ " is negative relevant with the partner-supplier's marginal revenue (i.e. $M R_{s}$ ) and his leverage rate of CSR efforts $\beta$.

Finally, in the same way from differentiation,

$$
\frac{\partial \pi_{m}}{\partial e_{m}}=\frac{\partial\left\{M R_{m} \cdot\left[D_{0}-e_{m}^{-\alpha}\left(e_{s}^{* *}\right)^{-\beta}\right]-e_{m}-r\left(e_{s}^{* *}\right)\right\}}{\partial e_{m}}=0
$$

Consequently, we have the following Stackelberg equilibrium policies,

$$
\begin{aligned}
& \left\{\begin{array}{l}
e_{m}^{* *}=\left[\alpha^{\beta+1}\left(\frac{1}{\beta}\right)^{\beta} \cdot\left(M R_{m}-\beta \cdot M R_{s}\right)\right]^{\frac{1}{\alpha+\beta+1}}, \\
\frac{M R_{m}}{M R_{s}} \geq \beta+1
\end{array}\right. \\
& \left\{\begin{array}{l}
e_{s}^{* *}=\left[\beta^{\alpha+1}\left(\frac{1}{\alpha}\right)^{\alpha} \cdot\left(M R_{m}-\beta \cdot M R_{s}\right)\right]^{\frac{1}{\alpha+\beta+1}}, \\
\frac{M R_{m}}{M R_{s}} \geq \beta+1
\end{array}\right.
\end{aligned}
$$

As $\alpha \geq 0, \beta \geq 0$ and $\frac{M R_{m}}{M R_{s}} \geq \beta+1$, then the following 
propositions may be given,

[Proposition 6] The firm's optimal strategy $e_{m}^{* *}$ is positive relevant with his marginal revenue (i.e. $M R_{m}$ ) and leverage rate of CSR efforts $\alpha$, whereas negative relevant with the partner's marginal revenue (i.e. $M R_{s}$ ) and the leverage rate of CSR efforts $\beta$.

[Proposition 7] The firm's optimal strategy $e_{s}^{* *}$ is positive relevant with his marginal revenue (i.e. $M R_{m}$ ) and leverage rate of CSR efforts $\beta$, whereas negative relevant with the partner's marginal revenue (i.e. $M R_{s}$ ) and the leverage rate of CSR efforts $\alpha$.

\section{Comparisons and Managerial Insights}

Aggregating the results from Proposition 1 to Proposition 7 , it can be reached that the "share rate $r$ " of the total investment of upstream partner-supplier's CSR efforts shall be the critical contract clause to coordinate the socially responsible supply chain partnership to implement Pareto optimal policy with cost sharing contract. Moreover, since $r^{* *}=1-1 /\left(M R_{m} / M R_{s}-\beta\right)$, this implies that the "share rate $r$ " has the strong positive relativity with the ratio of marginal revenues between supply chain members (i.e. $M R_{m} / M R_{s}$ ), whereas negative relativity with the partner-supplier's leverage rate of CSR efforts (i.e. $\beta$ ) under the condition of $M R_{m} / M R_{s} \geq \beta+1$.

In order to compare the above policies in non-cooperative static games and cost sharing contract coordination strategy, consider the following groups of parameter values:

1) Letting $\alpha>\beta$, while $M R_{s}$ is constant and $M R_{m} / M R_{s}$ is variable and then considering the case of $\alpha=0.6, \beta=0.4, M R_{s}=0.5$;

2) Letting $\alpha<\beta$, while $M R_{s}$ is constant and $M R_{m} / M R_{s}$ is variable and then considering the case of $\alpha=0.4, \beta=0.6, M R_{s}=0.5$.

Then the respective numerical results, including the optimal investment strategies on CSR efforts of the two members and the total system revenue in the socially responsible supply chain, are illustrated in Figures $\mathbf{2}$ and 3.

When comparing these figures, it should be noted that the socially responsible supply chain shall gain the more system revenue via the cost sharing contract coordination strategy, even if this implies that both of the two partners shall invest the more on CSR efforts $e_{m}$ and $e_{s}$, respectively.

However, as the Stackelberg leader, the socially responsible manufacturer shall make the effective contract clause "share rate $r$ " to promote the upstream partnersupplier to increase CSR efforts even with increasing manufacturer's marginal revenue (i.e. $M R_{m}$ ). In this way, the socially responsible supply chain shall gain the more system revenue than the non-cooperative static games

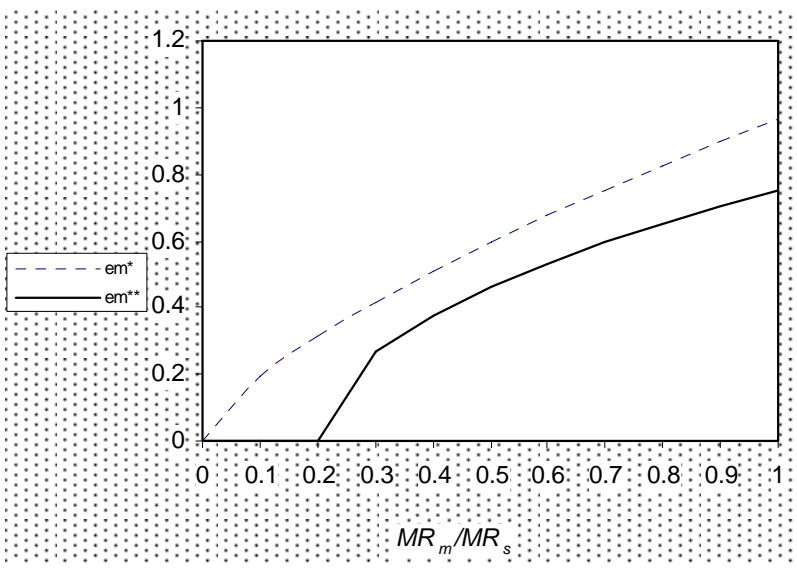

(a)

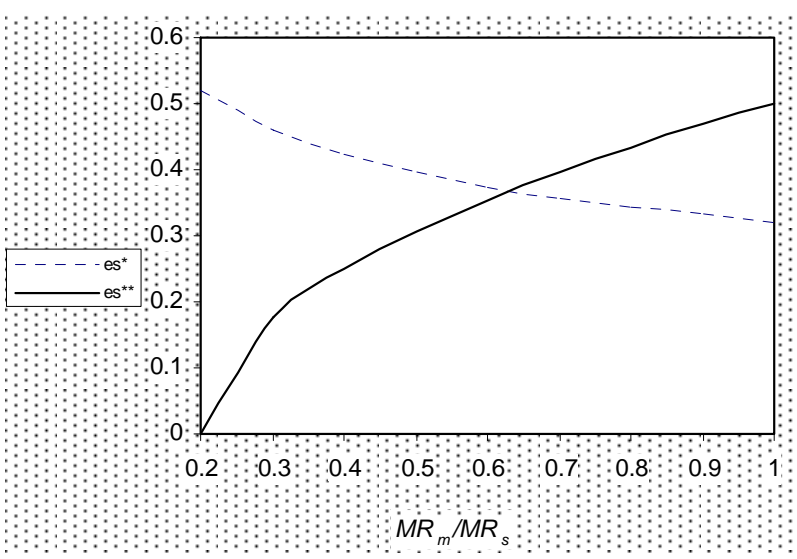

(b)

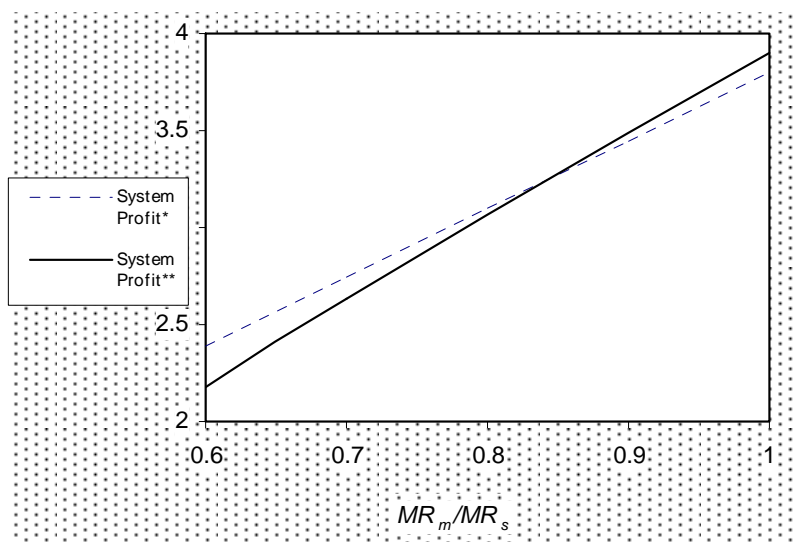

(c)

Figure 2. The numerical results in non-cooperative static games vs. cost sharing contract coordination strategy as $\alpha=$ 0.6, $\beta=0.4, M R_{s}=0.5$. (a) Firm's investment strategies on CSR efforts with $M R_{m} / M R_{s}$; (b) Supplier's investment strategies on CSR efforts with $M R_{m} / M R_{s}$; (c) System profit with $M R_{m} / M R_{s}$

whereas taking advantage of the less investment on CSR efforts $e_{m}$.

The key managerial insight derived from this study is that the "share rate $r$ " shall be the critical contract clause 


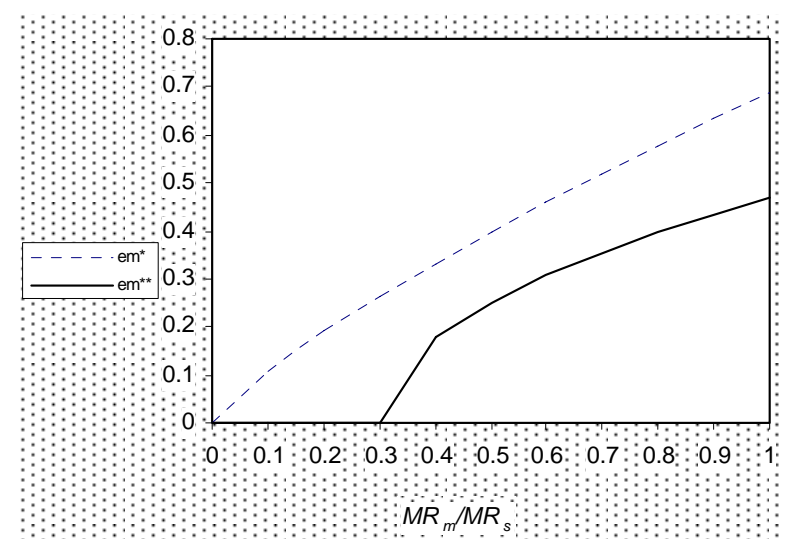

(a)

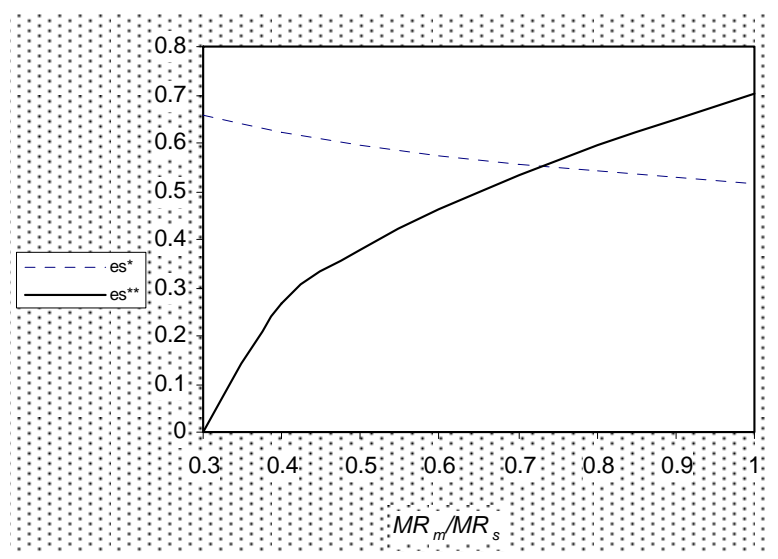

(b)

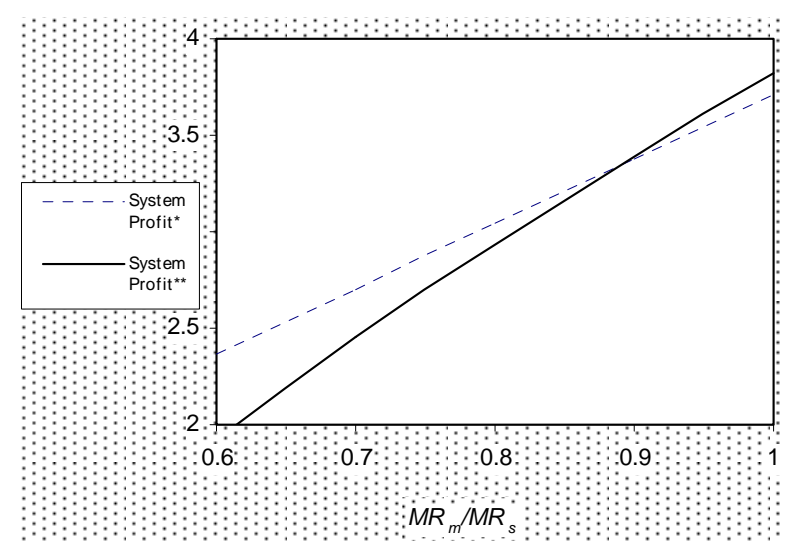

(c)

Figure 3. The numerical results in non-cooperative static games vs. cost sharing contract coordination strategy as $\alpha=$ 0.4, $\beta=0.6, M R_{s}=0.5$. (a) Firm's investment strategies on CSR efforts with $M R_{m} / M R_{s}$; (b) Supplier's investment strategies on CSR efforts with $M R_{m} / M R_{s}$; (c) System profit with $M R_{m} / M R_{s}$.

to coordinate the socially responsible supply chain partnership to implement Pareto optimal policy with cost sharing contract. Moreover, the "share rate $r$ " has a strong positive relativity with the ratio of marginal revenues between supply chain members, whereas negative relativity with the partner-supplier's leverage rate of CSR efforts.

\section{Concluding Remarks}

The purpose of this paper is to develop a five-step CSR Equity framework based-on socially responsible customer perspective for modeling and analysis of socially responsible supply chain partnership and show relevant optimal coordination strategies to the economic, social and environmental performance of all partners in the socially responsible supply chain system.

Five critical components of the five-step CSR Equity framework based-on socially responsible customer perspective are presented as follows:

-To put in voluntary and sustainable CSR efforts;

- To build and enhance the positive and trustworthy corporate reputation in virtue of voluntary and sustainable CSR efforts to reconcile economic, social and environmental benefits;

- To create the strong and favorable CSR associations through corporate reputation transmission;

- To elicit and spread intense and desirable customer reactions to CSR initiatives;

- To forging and foster socially responsible customer loyalty, which can be broken down into two key dimensions: behavioral loyalty (as well as purchase loyalty) and attitudinal loyalty.

Both attitudinal loyalty and behavioral loyalty link to better socially responsible consumer intentions and consumer behavior. As a result, the socially responsible consumer would avoid buying products from companies that harm society and actively seek out products from companies that help society.

From all propositions in the socially responsible supply chain coordination strategy with cost sharing contract, it notes that the "share rate $r$ " shall be the critical contract clause to coordinate the socially responsible supply chain partnership to implement Pareto optimal policy with cost sharing contract. Moreover, the "share rate $r$ " has a strong positive relativity with the ratio of marginal revenues between supply chain members, whereas negative relativity with the partner-supplier's leverage rate of CSR efforts.

\section{REFERENCES}

[1] J. G. Chen, et al., "Research Report on Corporate Social Responsibility of China (2011)," Social Sciences Academic Press, Beijing, 2011.

[2] H. R. Bowen, "Social Responsibilities of the Businessman," Harpor \& Row, New York, 1953.

[3] Committee for Economic Development, "Social Responsibilities of Business Corporations," CED, New York, 1971. 
[4] A. B. Carroll, "A Three-Dimensional Conceptual Performance," Academy of Management Review, Vol. 4, No. 4, 1979, pp. 497-505.

[5] A. B. Carroll, "The Pyramid of Corporate Social Responsibility: Toward the Moral Management of Organizational Stakeholders," Business Horizons, Vol. 34, No. 4, 1991, pp. 39-48. doi:10.1016/0007-6813(91)90005-G

[6] R. E. Freeman, "Strategic Management: A Stakeholder Approach," Pitman, Boston, 1984.

[7] S. L. Wartick and P. L. Coghran, "The Evolution of the Corporate Social Performance Model," Academy of Management Review, Vol. 10, No. 4, 1985, pp. 758-769.

[8] J. Elkington, "Cannibals with Forks: The Triple Bottom Line of 21st Century Business," New Society Publishers, Gabriola Island, British Columbia, 1998.

[9] S. Hughes and R. Wilkinson, "The Global Compact: Promoting Corporate Responsibility?" Environmental Politics, Vol. 10, No. 1, 2001, p. 155. doi:10.1080/714000519

[10] Commission of the European Communities, "Promoting a European Framework for Corporate Social Responsibility," Green Paper No. COM (2001) 366, Brussels, 2001.

[11] E. R. Larson and B. Cox, "Social Accountability 8000: Measuring Workplace Conditions Worldwide," Quality Digest, CEPAA, New York, 2003.

[12] C. R. Carter and M. Dresner, "Environmental Purchasing and Supply Management: Crossfunctional Development of Grounded Theory," Journal of Supply Chain Management, Vol. 37, No. 3, 2001, pp. 12-27. doi:10.1111/j.1745-493X.2001.tb00102.x

[13] S. Roberts, "Supply Chain Specific? Understanding the Patchy Success of Ethical Sourcing Initiatives," Journal of Business Ethics, Vol. 44, No. 2-3, 2003, pp. 159-170. doi:10.1023/A:1023395631811

[14] C. R. Carter and M. M. Jennings, "The Role of Purchasing in Corporate Social Responsibility: A Structural Equation analysis," Journal of Business Logistics, Vol. 25, No. 1, 2004, pp. 145-186. doi:10.1002/j.2158-1592.2004.tb00173.x

[15] R. Wang, "Social Responsible Supply Coordinating Relationship and Strategies under Supply Chain," Proceedings of 12th International Conference on Management Science \& Engineering, Inchon, 20-21 July 2005, pp. 685-689.

[16] J. M. Cruz, "The Impact of Corporate Social Responsibility in Supply Chain Management: Multicriteria Decision-Making Approach," Decision Support Systems, Vol. 48, No. 1, 2009, pp. 224-236. doi:10.1016/j.dss.2009.07.013

[17] J. J. Griffin and J. F. Mahon, "The Corporate Social Performance and Corporate Financial Performance Debate: Twenty-Five Years of Incomparable Research," Business and Society, Vol. 35, No. 1, 1997, pp. 15-31

[18] R. M. Roman, S. Hayibor and B. R. Agle, "The Relationship between Social and Financial Performance: Repainting a Portrait," Business and Society, Vol. 38, No. 1, 1999, pp. 109-125. doi:10.1177/000765039903800105

[19] L. E. Preston and D. P. O'Bannon, "The Corporate So-
cial-Financial Performance Relationship: A Typology and Analysis," Business and Society, Vol. 36, No. 4, 1997, pp. 419-429. doi:10.1177/000765039703600406

[20] S. Kapoor and H. S. Sandhu, "Does It Pay to Be Socially Responsible? An Empirical Examination of Impact of Corporate Social Responsibility on Financial Performance," Global Business Review, Vol. 11, No. 2, 2010, pp. 185-208. doi:10.1177/097215091001100205

[21] S. A. Waddock and S. M. Graves, "The Corporate Social Performance-Financial Performance Link," Strategic Management Journal, Vol. 18, No. 4, 1997, pp. 303-319. doi:10.1002/(SICI)1097-0266(199704)18:4<303::AID-S MJ869>3.0.CO;2-G

[22] R. Makni, C. Francoeur and F. Bellavance, "Causality between Corporate Social Performance and Financial Performance: Evidence from Canadian Firms," Journal of Business Ethics, Vol. 89, No. 3, 2009, pp. 409-422. doi:10.1007/s10551-008-0007-7

[23] M. Orlitzky, F. L. Schmidt and S. L. Rynes, "Corporate Social and Financial Performance: A Meta-Analysis," Organization Studies, Vol. 24, No. 3, 2003, pp. 403-441. doi: $10.1177 / 0170840603024003910$

[24] F. E. Webster, "Determining the Characteristics of the Socially Conscious Consumer," Journal of Consumer Research, Vol. 2, No. 3, 1975, pp.188-196. doi: $10.1086 / 208631$

[25] J. A. Roberts, "Profiling Levels of Socially Responsible Consumer Behavior: A cluster Cluster Analytic Approach and Its Implications for Marketing," Journal of Marketing, Vol. 3, No. 4, 1995, pp. 97-116.

[26] L. A. Mohr and D. J. Webb, "Do Consumers Expect Companies to be Socially Responsible? The Impact of Corporate Social Responsibility on Buying Behavior," Journal of Consumer Affairs, Vol. 35, No. 1, 2001, pp. 4572. doi:10.1111/j.1745-6606.2001.tb00102.x

[27] S. Brammer and S. Pavelin, "Building a Good Reputation," European Management Journal, Vol. 22, No. 6, 2004, pp. 704-713. doi:10.1016/j.emj.2004.09.033

[28] C. J. Fombrun, "Building Corporate Reputation through CSR Initiatives: Evolving Standards," Corporate Reputation Review, Vol. 8, No. 1, 2005, pp. 7-11. doi:10.1057/palgrave.crr.1540235

[29] C. Hillenbrand and K. Money, "Corporate Responsibility and Corporate Reputation: Two Separate Concepts or Two Sides of the Same Coin," Corporate Reputation Review, Vol. 10, No. 4, 2007, pp. 261-277. doi:10.1057/palgrave.crr.1550057

[30] A. Smidts, T. H. Pruyn and C. B. M. Van Riel, "The Impact of Employee Communication and Perceived External Prestige on Organizational Identification," Academy of Management Journal, Vol. 44, No. 5, 2001, pp. 10511062. doi: $10.2307 / 3069448$

[31] T. J. Brown and P. A. Dacin, "The Company and the Product: Corporate associations and Consumer Product Responses," Journal of Marketing, Vol. 61, No. 1, 1997, pp. 68-84. doi:10.2307/1252190

[32] S. Sen and C. B. Bhattacharya, "Does Doing Good Always Lead to Doing Better? Consumer Reactions to 
Corporate Social Responsibility," Journal of Marketing Research, Vol. 38, No. 2, 2001, pp. 225-243.

[33] A. Chaudhuri and M. B. Holbrook, "The Chain of Effects from Brand Trust and Brand Affect to Brand Performance:
The Role of Brand Loyalty," Journal of Marketing, Vol. 65, No. 4, 2001, pp. 81-93.

doi:10.1509/jmkg.65.2.81.18255 